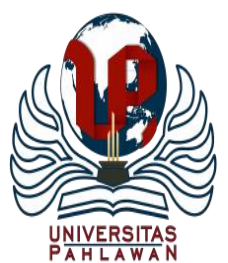

Edukatif : Jurnal Ilmu Pendidikan Volume 3 Nomor 5 Tahun 2021 Halm 2135 - 2145

EDUKATIF: JURNAL ILMU PENDIDIKAN

Research \& Learning in Education

https://edukatif.org/index.php/edukatif/index

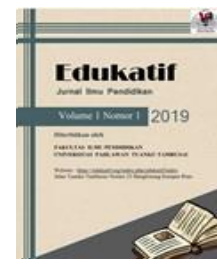

\title{
Strategi Pengembangan Kurikulum Perspektif Pendekatan Total Quality Management (Tqm) di Pendidikan Tinggi
}

\author{
Raqib Alamah Putra ${ }^{1 凶}$, Putri Restina Dewi², Ahmad Jalaludin ${ }^{3}$, \\ Abdul Malik Karim Amrullah ${ }^{4}$
}

PUniversitas Islam Negeri Maulana Malik Ibrahim Malang, Indonesia $a^{1,2,3,4}$

E-mail : putraraqibalamah@gmail.com ${ }^{1}$, putrirestina026@gmail.com ${ }^{2}$, ahmad.jalaludin2210@gmail.com $^{3}$, amkamutia@gmail.com ${ }^{4}$

\begin{abstract}
Abstrak
Penelitian ini bertujuan untuk mengetahui dan menganalisis strategi pengembangan kurikulum di perguruan tinggi berdasarkan pendekatan TQM yaitu pada komponen kualitas produk dan kepuasan pelanggan. Penelitian ini dilakukan menggunakan studi kepustakaan atau literature review. Studi kepustakaan sebagai metode yang menggunakan beberapa sumber keilmuan seperti buku, jurnal, artikel, karya ilmiah seperti tesis maupun hasil penelitian lainnya. Adapun teknik analisis data menggunakan proses deskripsi analitis terhadap literatur yang berkaitan dengan variabel penelitian. Berdasarkan penelitian yang dilakukan, kualitas produk dapat terbentuk dengan menggunakan, pertama: Model serial yang merupakan pendekatan yang menyusun mata kuliah berdasarkan logika struktur keilmuan. Mata kuliah disusun dari yang paling dasar menuju tingkat lanjutan. Dalam model ini dikenal istilah mata kuliah prasyarat, yang menunjukkan keterhubungan mata kuliah yang satu dengan yang lain. Kedua: Model paralel merupakan strategi penyusunan mata kuliah pada setiap semester sesuai dengan tujuan kompetensinya. Model ini setara dengan penggunaan sistem blok, penyusunan mata kuliah berdasarkan ketercapaian kompetensi bukan sekedar berorientasi pada pembelajaran semester. Kepuasan pelanggan terbentuk melalui lima prinsip, yaitu: Fokus pada Pelanggan, Keterlibatan Total, Pengukuran, Komitmen, dan Perbaikan Berkelanjutan.
\end{abstract}

Kata Kunci: Kurikulum, Total Quality Management (TQM).

\begin{abstract}
This study aims to determine and analyze the development of curriculum strategies in higher education with the TQM approach, namely the components of product quality and customer satisfaction. This research was conducted by using literature study or literature study. Literature study as a method that uses several scientific sources such as books, journals, articles, scientific works such as theses and other research results. The data analysis technique uses a descriptive analytical process to the literature related to the research variables. Based on the research conducted, product quality can be formed by using, first: Serial model which is an approach that compiles courses based on scientific structural logic. The courses are arranged from the most basic to the advanced level. In the model known as prerequisite courses, which show the relationship between one course and another. Second: Parallel model is a strategy for preparing courses in each semester in accordance with the objectives of competence. This model is equivalent to the use of the block system, the preparation of courses based on competency achievement is not only developed in semester learning. customers are formed through 5 components, namely: Customer Focus, Total Engagement, Measurement, Commitment, and Continuous Improvement.
\end{abstract}

Keywords: Curriculum, Total Quality Management (TQM).

Copyright (c) 2021 Raqib Alamah Putra, Putri Restina Dewi, Ahmad Jalaludin, Abdul Malik Karim Amrullah

$\triangle$ Corresponding author

Email : putraraqibalamah@gmail.com

DOI : https://doi.org/10.31004/edukatif.v3i5.715 
2136 Strategi Pengembangan Kurikulum Perspektif Pendekatan Total Quality Management (Tqm) di Pendidikan Tinggi - Raqib Alamah Putra, Putri Restina Dewi, Ahmad Jalaludin, Abdul Malik Karim Amrullah

DOI: https://doi.org/10.31004/edukatif.v3i5.715

\section{PENDAHULUAN}

Perguruan Tinggi atau Universitas saat ini memiliki predikat sebagai tingkat tertinggi dalam hirarki pendidikan. Oleh karenanya, proses pembelajaran diharapkan memiliki kualitas baik dari segi kurikulum maupun model pembelajarannya. Hal ini bertujuan agar mahasiswa medapatkan pelayanan pendidikan secara maksimal serta dapat memahami materi pada setiap mata kuliah secara komprehensif. Dalam perspektif Pembangunan Pendidikan Nasional, pendidikan tinggi harus lebih berperan dalam membangun seluruh potensi manusia agar menjadi subjek yang berkembang secara optimal dan bermanfaat bagi masyarakat dan pembangunan nasional (Alhamuddin, 2016). Berdasarkan Peraturan Presiden No. 8 tahun 2012 tentang Kerangka Kualifikasi Nasional Indonesia (KKNI), dan Permendikbud No. 49 tahun 2014 tentang Standar Nasional Pendidikan Tinggi, memberikan pesan bahwa pendidikan tinggi harus mampu melahirkan sumber daya mnausia yang cakap, berkarakter, dan berdaya saing. Pendidikan tinggi juga berfungsi mengembangkan kemampuan dan membentuk watak serta peradaban bangsa yang bermartabat dalam rangka mencerdaskan kehidupan bangsa (Kemendikbud, 2012). Selain itu, pendidikan tinggi harus mampu memberdayakan mahasiswa menjadi manusia terdidik (educated person) yang berpengetahuan, kreatif, inovatif, dan berkarakter (Academy, 2012). Untuk mewujudkan hal tersebut pendidikan tinggi membutuhkan strategi pengembangan kurikulum yang tepat.

Kurikulum merupakan seperangkat pengaturan dan rencana mengenai tujuan, isi, bahan pelajaran serta cara yang digunakan untuk pedoman penyelenggaraan kegiatan pembelajaran agar dapat tercapai tujuan pendidikan (Sukmadinata, 2012). Kurikulum juga merupakan seperangkat rencana dan pengaturan mengenai capaian pembelajaran lulusan, bahan kajian, proses, dan penilaian yang digunakan sebagai pedoman penyelenggaraan program studi (Direktorat Pendidikan Tinggi Keagamaan Islam, 2018). Kurikulum sebagai serangkaian program pendidikan yang disediakan oleh lembaga pendidikan agar memperoleh hasil belajar yang efektif, efisien dan hasil yang sesuai dengan visi, misi, tujuan lembaga pendidikan. Selanjutnya kurikulum pendidikan tinggi perlu dikembangkan berdasarkan kebutuhan di masyarakat, bangsa, dan negara. Hal itu dimaksudkan agar pendidikan tinggi dapat menjawab tuntutan perubahan sesuai dengan jamannya. Dengan demikian outcome atau keluaran pendidikan tinggi akan mampu memberikan kontribusi secara optimal dalam upaya membangun masyarakat berbasis pengetahuan (knowledge based society).

Namun, dalam praktiknya perguruan tinggi kurang memperhatikan sisi pengembangan kurikulum, artinya pengembangan yang dilakukan hanya bersifat struktural tanpa ada inovasi didalamnya. Hal tersebut berimplikasi pada outcome pendidikan tinggi yang dinilai kurang berkualitas dibuktikan dengan terus meningkatnya jumlah pengangguran dari pendidikan tinggi. Berdasarkan data Badan Pusat Statistik (BPS) dalam setahun terakhir, jumlah pengangguran meningkat 60 ribu orang hingga pada Februari 2020. Fenomena tersebut telah menjadi polemik atau permasalahan di perguruan tinggi yang terjadi dalam beberapa tahun ini. Selain itu perkembangan modernisasi juga memberikan dorongan bagi pendidikan tinggi agar terus membenahi diri sehingga para lulusan yang dihasilkan dapat bersaing didunia kerja, sebagaimana pendapat (Sayyi. Ach, 2017) bahwa adanya konflik antar tradisi pemikiran dan pendidikan dengan modernitas. Pendidikan tinggi tidak seharusnya bertahan pada zona nyaman dengan tetap mempertahankan sistem tradisional salah satunya pada aspek kurikulum, namun harus bersifat dinamis menyesuaikan dengan kebutuhan zaman. Dengan demikian perlu adanya inovasi dan penataan dalam pendidikan tinggi sebagaimana (Yusuf \& Sohiron, 2019) menyatakan implementasi kurikulum dalam pembelajaran di pendidikan tinggi perlu menggunakan pola baru agar terjadi perubahan dan penataan yang semakin baik. Oleh karenanya, penelitian ini berangkat dari dua fenomena yaitu rendahnya kualitas lulusan pendidikan tinggi dan tuntutan pendidikan tinggi agar menyesuaikan dengan kedinamisan zaman. Pengembangan kurikulum pendidikan tinggi seyogyanya diimplementasikan dengan konsep strategi yang berorientasi pada kualitas outcome. Selain mempertimbangkan unsur kesesuaian, dalam prosesnya kurikulum membutuhkan strategi pengembangan 
tersendiri, agar setiap target dan tujuan dapat tercapai dengan maksimal terutama di lingkungan perguruan tinggi.

Pada penelitian sebelumnya pembahasan mengenai pengembangan kurikulum hanya bersifat kajian filosofis dan normatif sebagaimana dalam penelitian (Hanafi, 2016; Marwan, 2014). Sedangkan dalam penelitian ini fokus utama membahas tentang strategi pengembangan kurikulum secara praktis yang berorientasi pada kualitas lulusan, selanjutnya untuk mewujudkannya menggunakan perspektif Total Quality Management (TQM). Dengan demikian, adanya pengembangan strategi kurikulum yang tepat dapat meningkatkan kualitas mahasiswa secara akademik sehingga dapat bertahan dalam persaingan global sehingga meningkatkan kepuasan pelayanan pembelajaran sebagaimana dalam perspektif Total Quality Management (TQM) yaitu berorientasi pada kualitas produk (outcome) dan kepuasan pelanggan dalam hal ini adalah mahasiswa (Khoiri, 2016). Dengan demikian, pengembangan kurikulum dengan pendekatan TQM dapat menjadi salah satu solusi dalam menjawab polemik rendahnya kualitas outcome pendidikan tinggi.

Berdasarkan paparan sebelumnya, pembahasan mengenai strategi pengembangan kurikulum perspektif TQM menjadi penting untuk dilakukan sebagai bentuk problem solving dalam fenomena yang telah dijelaskan. Adapun fokus dalam penelitian ini terdiri dari: 1). Strategi pengembangan kurikulum di perguruan tinggi, 2). Strategi pengembangan kurikulum dalam perspektif TQM. Sedangkan tujuan penelitian ini adalah untuk menganalisis strategi pengembangan kurikulum di perguruan tinggi berdasarkan perspektif pendekatan TQM yaitu pada komponen kualitas produk dan kepuasan pelanggan.

\section{METODE PENELITIAN}

Metode penelitian yang digunakan yaitu menggunakan studi kepustakaan atau literature review. Studi kepustakaan sebagai metode yang menggunakan beberapa sumber keilmuan seperti buku, jurnal, artikel, karya ilmiah seperti tesis maupun hasil penelitain untuk menemukan jawaban dari fokus masalah pada penelitian ini. Adapun teknik analisis data menggunakan proses deskriptis analitis terhadap literatur yang berkaitan dengan variabel penelitian. Berikut rancangan pada penelitian ini: 

Tinggi - Raqib Alamah Putra, Putri Restina Dewi, Ahmad Jalaludin, Abdul Malik Karim Amrullah DOI: https://doi.org/10.31004/edukatif.v3i5.715

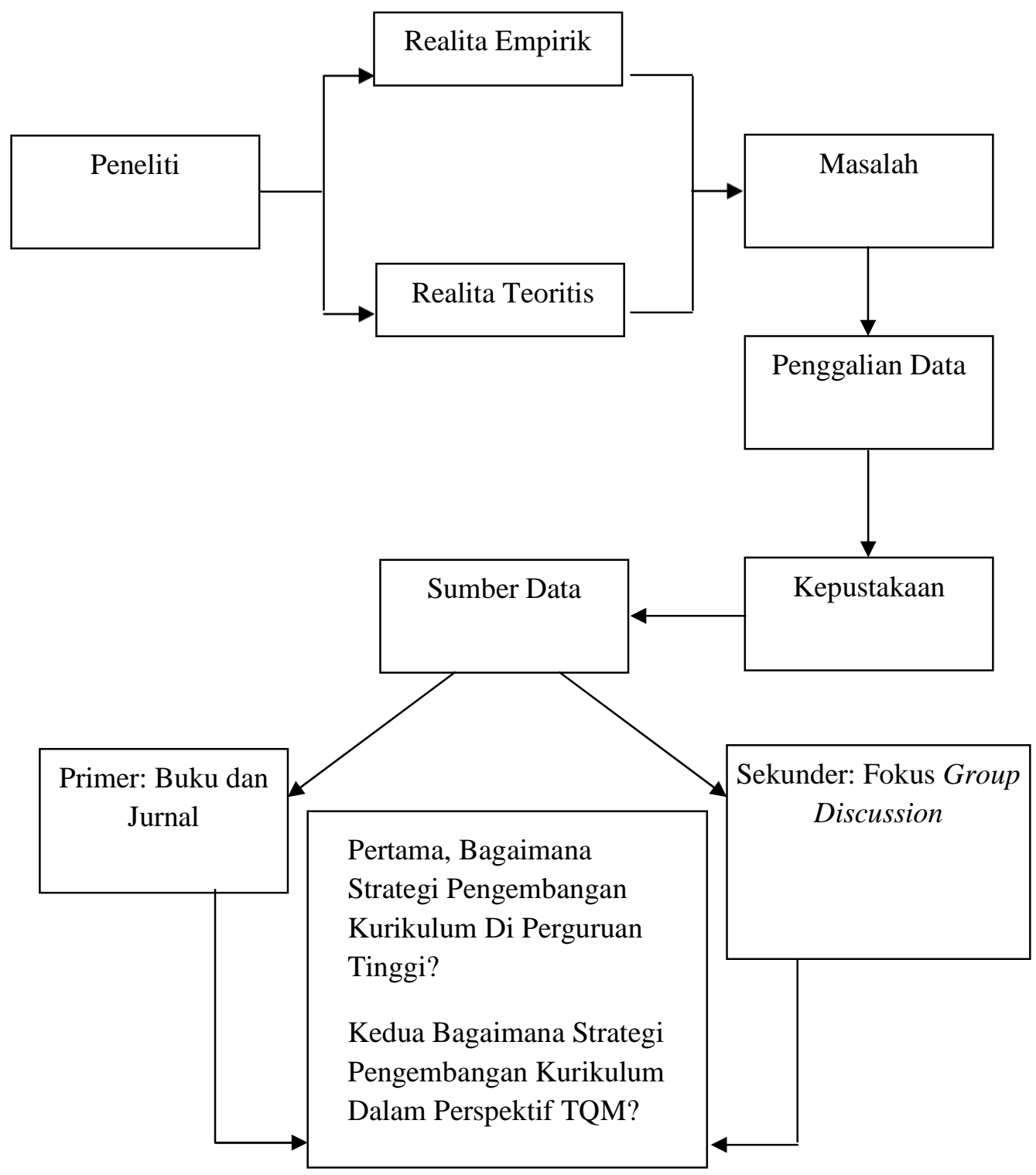

Gambar 1. Bagan Rancangan Penelitian

Penelitian ini berangkat dari permasalahan berdasarkan fakta empirik dan fakta teoritis tentang rendahnya kualitas outcome pendidikan tinggi dibuktikan dengan meningkatnya angka pengangguran serta kebutuhan terhadap pendidikan tinggi yang semakin dinamis. Dalam hal ini, peneliti menemukan bahwa perlunya strategi pengembangan kurikulum di perguruan tinggi dengan melihat perspektif pendekatan total quality management (TQM) di pendidikan tinggi sebagai solusi atas problematika tersebut. Dengan demikian,, peneliti menemukan beberapa masalah yang harus dipecahkan melalui beberapa fokus diantaranya Pertama, strategi pengembangan kurikulum di perguruan tinggi. Kedua, strategi pengembangan kurikulum dalam perspektif TQM masalah teersebut telah mendorong peneliti untuk mengumpulkan dan menggali data berdasarkan fokus dalam penelitian ini. Sumber data yang dibedakan menjadi dua macam, yaitu sumber data primer (buku dan jurnal terkait dan sumber data sekunder (Focus Group Discussion dan penelitian terdahulu). Data-data tersebut dianalisis untuk menemukan bagaimana konsep strategi pengembangan kurikulum dengan perspektif pendekatan total quality management (TQM) di pendidikan tinggi. Hasil dari analisia akan diuraikan untuk menjawab masalah yang telah dirumuskan. 
Dalam penelitian ini, pengumpulan data diperoleh dari berbagi literatur jurnal online, serta artikelartikel ilmiah. Peneliti melakukan pengembangan penelitian dengan menggunakan keyword Pengembangan Kurikulum dan perspektif Total Quality Management (TQM). Berdasarkan pengembangan keyword tersebut peneliti memperoleh berbagai macam jurnal online dan artikel ilmiah, kriteria yang diperoleh dan dipilih berdasarkan pembahasan tentang Pengembangan Kurikulum perspektif Total Quality Management (TQM). Terdapat 20 sumber yang menjadi rujukan utama, literature tersebut dianalisis yang paling relevan dan peroleh 17 jurnal online terakreditasi beberapa diantaranya merujuk pada penelitian (Alhamuddin, 2016; Helaluddin, 2018; Kaimuddin, 2015; Wafi, 2017). Selanjutnya merujuk pada beberapa kebijakan pemerintah maupun artikel ilmiah beberapa diantaranya (Direktorat Pendidikan Tinggi Keagamaan Islam, 2018; Kemendikbud, 2012; Sukmadinata, 2012).

Teknik analisis yang dilakukan pada penelitian dengan dokumentasi, dimana data yang dianalisis mengenai hal-hal atau variabel yang berupa artikel ilmiah jurnal, buku, dan catatan-catatan lainnya. Dalam pengolahan data yang dianalisis menggunakan model pengumpulan data, reduksi data (melakukan pemilihan, memfokuskan, penyerdehanaan untuk mendapatkan temuan data dalam penelitian tersebut), display data, dan penelitian kesimpulan atau verifikasi.

\section{HASIL DAN PEMBAHASAN PENELITIAN}

\section{Strategi Pengembangan Kurikulum di Perguruan Tinggi}

Berkaitan dengan pengembangan strategi kurikulum terdapat dua model struktur yang dapat digunakan dalam menyusun kurikulum, yakni model serial dan model paralel (Kemendikbud, 2014). Model serial merupakan pendekatan yang menyusun mata kuliah berdasarkan logika struktur keilmuan. Mata kuliah disusun dari yang paling dasar menuju tingkat lanjutan. Dalam model ini dikenal istilah mata kuliah prasyarat, yang menunjukkan keterhubungan mata kuliah yang satu dengan yang lain. Adapun model paralel merupakan strategi penyusunan mata kuliah pada setiap semester sesuai dengan tujuan kompetensinya. Model ini setara dengan penggunaan sistem blok, penyusunan mata kuliah berdasarkan ketercapaian kompetensi bukan sekedar berorientasi pada pembelajaran semester. Berikut bagan yang menjelaskan sistematika model serial dan paralel dalam strategi pengembangan kurikulum: 


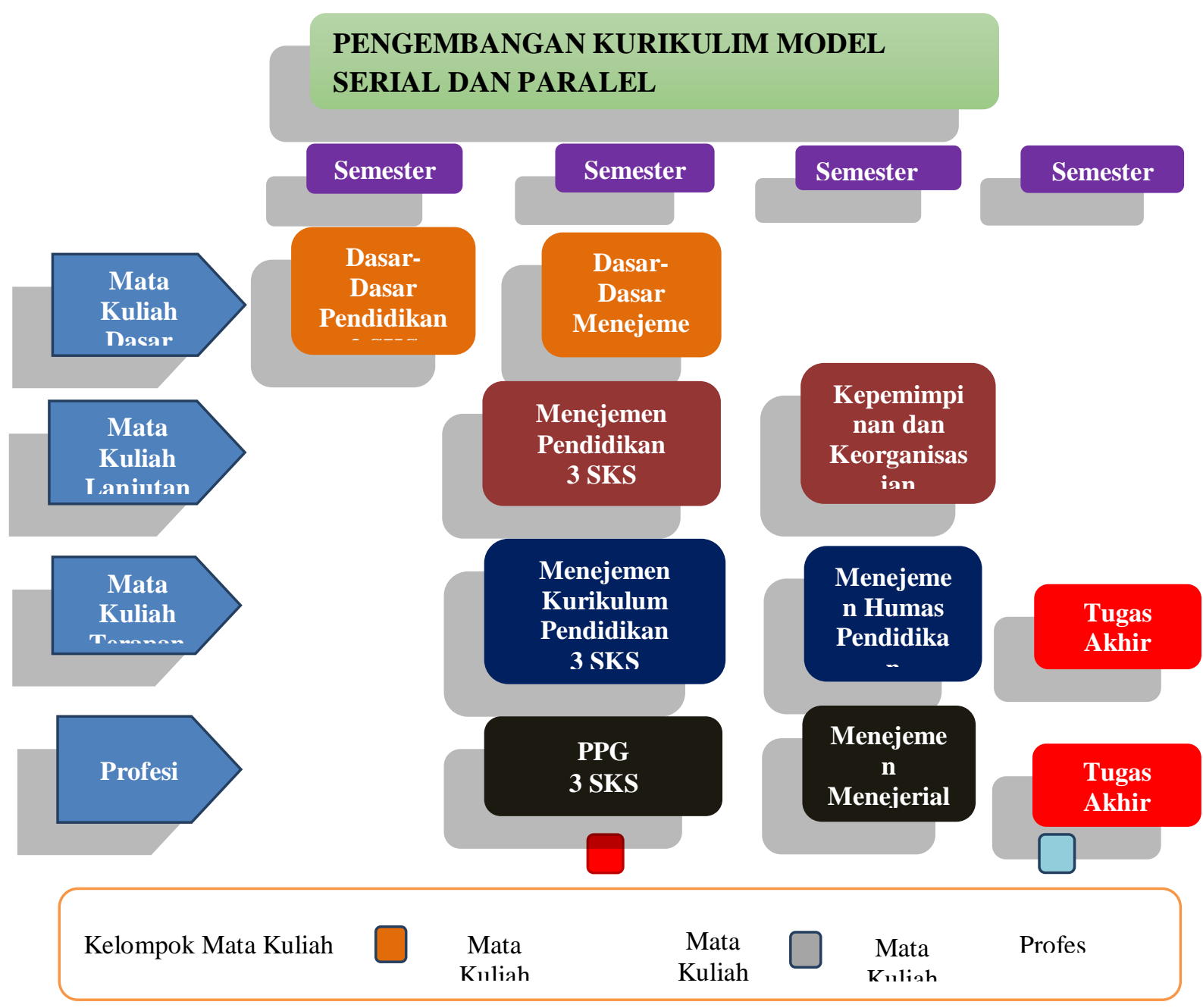

Gambar 2. Bagan Model Serial dan Paralel

Selain dua model tersebut, terdapat model lain yang dapat diterapkan, yaitu model konsekutif dan model konkuren, kedua model ini diterapkan untuk pendidik (Dikti, 2014). Model konsekutif merupakan penyusunan struktur mata kuliah secara berurutan dengan memperhatikan capaian pembelajaran. Ada perbedaan yang tegas antara penguasaan kompetensi keilmuan dan kompetensi pedagogik. Selanjutnya model konsekutif menawarkan strategi dengan pendidik yang didesain menjadi (4+1), yakni empat tahun fokus pada penguasaan kompetensi keilmuan dan satu tahun kompetensi profesi. Adapun model konkuren menyusun kurikulum yang mengintegrasikan antara kompetesi keilmuan dan kompetensi profesi pada saat yang bersamaan, sebagaimana yang selama ini dilakukan di lembaga pendidikan tenaga kependidikan (Maksum, 2015). Berikut gambaran model konsekutif dan konkuren dalam startegi pengembangan kurikulum pendidikan tinggi. 


\begin{tabular}{|c|c|}
\hline & $\begin{array}{c}\text { Consecutive Model } \\
\& \\
\text { Concurrent Model }\end{array}$ \\
\hline \multicolumn{2}{|r|}{ Integrasi } \\
\hline Mata Kuliah Keilmuan & Mata Kuliah Profesi \\
\hline Kurikulum & \multirow[t]{2}{*}{ Kewirausahaan } \\
\hline Sumber Daya Manusia & \\
\hline Hubungan Masyarakat & \multirow[t]{2}{*}{ Manajerial atau manajemen } \\
\hline Mutu & \\
\hline Kurikulum Entrepreneurship & Capaian Kompetensi \\
\hline Manajemen Sumber Daya Manusia & Kriteria Kelulusan \\
\hline Manajemen Hubungan Masyarakat & Standar Kelulusan Nilai \\
\hline Manajemen Mutu & Sistem Kredit Semester (SKS) \\
\hline
\end{tabular}

Gambar 3. Bagan Model Konsekutif dan Konkuren

Pada perkembangannya kurikulum menjadi dokumen rancangan pembelajaran dan kurikulum dalam implementasinya (in action), seringkali kurikulum sebagai dokumen telah tersusun dengan begitu baik, namun pelaksanaannya jauh dari yang di harapkan (Helaluddin, 2018). Dalam konteks ini, peran pengelola kurikulum yaitu ketua program studi dan peran pelaksana kurikulum yakni dosen menjadi sangat penting. Terdapat korelasi yang sangat kuat antara kepemimpinan akademik dan kualitas dosen terhadap keberhasilan pelaksanaan kurikulum sehingga dapat memaksimalkan capaian pembelajaran mata kuliah yang meliputi sikap dan tata nilai, kemampuan kerja, penguasaan pengetahuan, wewenang dan tanggungjawab (Nurdin, 2018). Semakin tinggi komitmen kaprodi dan dosen dalam melaksanakan kurikulum, semakin tinggi peluang keberhasilan dalam mencapai target dan tujuan yang telah ditentukan.

Setiap intitusi perguruan tinggi dan dosen pengajar memiliki alasan dan pertimbangan sendiri untuk memilih model pembelajaran yang paling sesuai dengan setiap mata kuliah yang ada untuk diselenggarakan pada proses pembelajaran. Faktor utama yang seharusnya dipertimbangan dalam menetapkan pilihan model pembelajaran yang digunakan pada setiap perguruan tinggi adalah faktor pencapaian hasil belajar, selain faktor lingkungan belajar dan biaya operasional. Faktor lingkungan belajar dapat dipertimbangkan dalam pemilihan model pembelajaran mata kuliah tertentu di perguruan tinggi, karena dengan lingkungan belajar yang cocok bagi mahaiswa tertentu namun tidak didukung dengan model pembelajaran yang yang tepat, maka akan berdampak menjadi kesulitan belajar bagi mahasiswa pada akhirnya akan berimplikasi pada kegagalan dalam mencapai hasil belajar dalam proses perkuliahan. Secara jangka pendek dan jangka panjang, model pembelajaran tatap memerlukan biaya yang relatif cukup besar dalam penyelengaraaan pembelajaran. Dengan demikian kurikulum dalam suatu pendidikan tinggi memiliki peran yang dapat menentukan tercapainya tujuan pendidikan (Wafi, 2017). Adapun pada Kurikulum Berbasis Kompetensi terdiri dari kurikulum inti dan institusional. Dalam mengimplementasikan Kurikulum Berbasis Kompetensi ditetapkan kompetensi utama oleh kesepakatan bersama antara kalangan perguruan tinggi, masyarakat profesi, dan pengguna lulusan. Sedangkan kompetensi pendukung lainnya, ditetapkan oleh perguruan tinggi sendiri (Kaimuddin, 2015). 
2142 Strategi Pengembangan Kurikulum Perspektif Pendekatan Total Quality Management (Tqm) di Pendidikan Tinggi - Raqib Alamah Putra, Putri Restina Dewi, Ahmad Jalaludin, Abdul Malik Karim Amrullah

DOI: https://doi.org/10.31004/edukatif.v3i5.715

\section{Pengembangan Kurikulum Dalam Perspektif Pendekatan TQM}

Goestsch dan Davis mendefinisikan TQM sebagai suatu pendekatan dalam menjalankan suatu usaha dengan memaksimalkan daya saing melalui penyempurnaan secara terus menerus dari produk, jasa, manusia, proses, dan lingkungan organisasi (Sonia, 2021). Total Quality Management (TQM) merupakan paradigma baru yang menjadi tren dalam berbagai aspek kehidupan, TQM diimplementasikan dalam setiap organisasi baik yang bersifat profit maupun nonprofit, berskala kecil maupun besar, dalam lingkup lokal maupun global. Sehingga dalam aspek pendidikan saat ini TQM telah implementasikan dalam proses pengelolaan lembaga pendidikan, akan tetapi penerapan TQM dalam pendidikan tidak hanya fokus pada kegiatan manajemen, akan tetapi menyentuh aspek pembelajaran dan pembentukan kepribadian sebagai karakteristik unik yang tidak dapat dikelola secara umum. Diperlukan perlakuan khusus yang dapat menyatukan hasil pembelajaran yaitu kepribadian intelektual sebagai nilai fundamental dan keterampilan sebagai nilai instrumental. TQM memiliki fokus pada perbaikan yang berkelanjutan, seperti perbaikan diri, peningkatan pekerjaan dan peningkatan komunitas dan masyarakat dalam ranah pendidikan. Langkah pertama untuk menerapkan TQM dalam pengaturan pendidikan tinggi hendaknya mengadopsi kerangka kerja TQM yang relevan yang memenuhi misi dan tujuannya (Wibowo et al., 2020).

Optimalisasi pencapaian tujuan-tujuan pendidikan memerlukan pendekatan dan pengelolaan tertentu dalam mengembangkan kurikulumnya, sehingga kualitas lembaga pendidikan tinggi dapat terus ditingkatkan. TQM sebagai salah satu pendekatan dalam manajemen kualitas perlu diimplementasikan dalam pengembangan kurikulum lembaga pendidikan tinggi. Beberapa pilar utama TQM yang dapat diimplementasikan kedalam pengembangan kurikulum pendidikan tinggi, meliputi atas fokus pada pelanggan, keterlibatan total, pengukuran hasil, komitmen dan perbaikan terus menerus (Khoiri, 2016). Berdasarkan pendapat dalam mewujudkan total quality dalam lembaga pendidikan tinggi, implementasi TQM dalam pengembangan kurikulum perlu menjadi pertimbangan dengan menerapkan langkah stategis melalui prinsip TQM berikut ini:

Fokus pada Pelanggan. Memuaskan harapan pelanggan (mahasiswa) berarti mengantisipasi kebutuhan pelanggan pada masa datang. Pendidikan tinggi perlu mengembangkan fokus kualitas, setiap orang dalam sistem PT selayaknya mengakui bahwa setiap output pendidikan tinggi adalah costumer.

Keterlibatan Total. Prinsip TQM dalam pengembangan kurikulum adalah setiap individu harus terlibat dalam transformasi kualitas. Manajemen mesti memiliki komitmen untuk menfokuskan pada kualitas, harus mendorong staf dan mahasiwa untuk mengubah cara kerja lama kepada cara kerja baru. Pengukuran. Dalam pengembangan TQM, pengukuran merupakan salah satu langkah yang penting dalam proses manajemen. Pengukuran secara tradisional yaitu melalui ukuran kualitas atas luaran lembaga pendidikan tinggi berdasarkan prestasi mahasiswa. Komitmen. Implementasi manajemen kualitas dalam lembaga pendidikan tinggi diperlukan komitmen terhadap kualitas dan perbaikan kualitas. Total kualitas pendidikan adalah suatu perubahan budaya organisasi sebagai cara baru bagi perbaikan kehidupan setiap individu. Perbaikan Berkelanjutan. Konsep dasar kualitas adalah segala sesuatu dapat diperbaiki. Kualitas didasarkan pada konsep bahwa setiap proses dapat diperbaiki dan tidak ada proses yang sempurna. Sehingga proses perbaikan seharusnya dilaksanakan secara berkesinambungan melalui proses kerja sama yang baik.

Pengembangan kurikulum yang berkualitas di pendidikan tinggi dapat tercapai melalui proses impelemntasi secara daya guna atau efisiensi, dipercaya (realiability) dan handal. Dalam hal ini kualitas pendidikan tinggi diharapkan memiliki karakteristik yaitu berupa kesesuaian antara kualitas outcome dengan harapan masyarakat. Pengembangan kurikulum memiliki kedudukan yang penting dalam mencetak lulusan (Suwadi, 2016). Selanjutnya Kotler dalam mengungkapkan formulasi dalam mengatur strategi pengembangan kurikulum dengan beberapa landasan sebagai berikut: (1) Loyalitas pelanggan pendidikan yang lebih tinggi (higher customer loyalty). Kualitas sebagai faktor penting dalam menciptakan outcome di pendidikan tinggi, dalm hal ini kualitas berimplikasi pada kepuasan akan membentuk loyalitas yang tinggi. Hal tersebut akan 

Tinggi - Raqib Alamah Putra, Putri Restina Dewi, Ahmad Jalaludin, Abdul Malik Karim Amrullah DOI: https://doi.org/10.31004/edukatif.v3i5.715

berpengaruh pada meningkatkan pemasaran dan peningkatan sumber dana pendidikan tinggi. (2) Penyebaran pada pasar yang lebih besar (higher market share). Loyalitas pelanggan (mahasiswa) menjadi dasar bagi organisasi, hal tersebut disebabkan menggunakan model pengiklanan yang berkualitas sehingga dapat memperluas pasar. (3) Hasil investasi yang lebih tinggi (higher returns to investment). Lembaga pendidikan tinggi yang memiliki outcome berkualitas secara tidak langsung akan diminati masyarakat sehingga dapat bersaing di pasar kerja. (4) Loyalitas karyawan (loyal employee). Lembaga pendidikan tinggi yang berkualitas berdampak pada rasa bangga dari civitas akademika, selanjutnya akan berimplikasi pada peningkatan loyalitas dan produktivitas karyawan. (5) Biaya rendah (lower cost).

Berikut bagan hasil temuan pengembangan kurikulum (model serial) pada perspektif TQM di pendidikan tinggi:

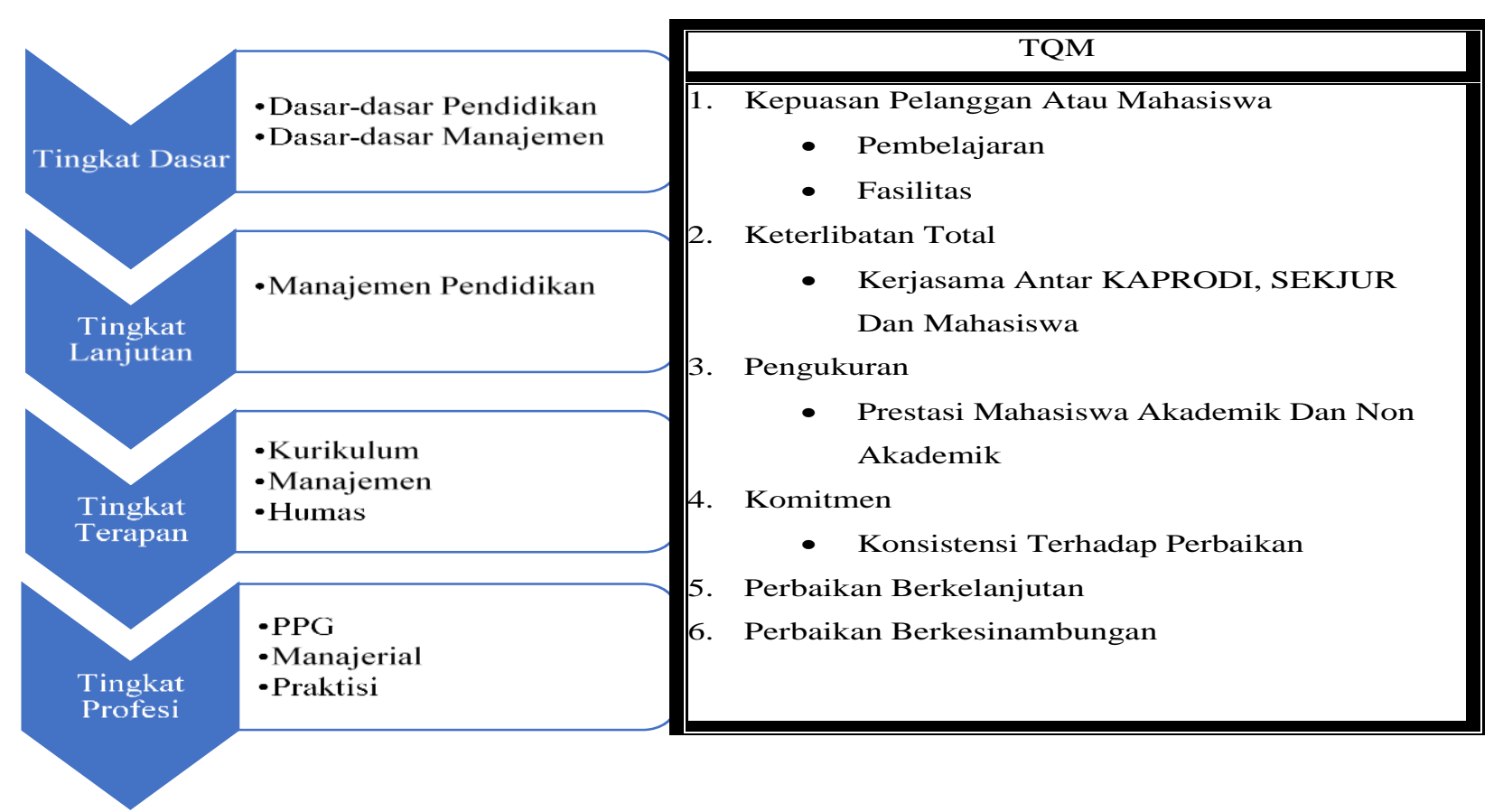

\section{Gambar 4. Bagan Hasil Temuan Pengembangan Kurikulum (Model Serial) Perspektif TQM}

Bagan tersebut menjelaskan salah satu model pengembangan kurikulum (model serial) diterapkan melalui pendekatan TQM. Model serial sebagai bentuk pengembangan kurikulum dengan menyusun mata kuliah berdasarkan tingkat keilmuan mulai dari tingkat dasar hingga tingkat tertinggi (profesi). Sedangkan dalam pendekatan TQM secara umum memiliki fokus pada hasil lulusan bedasarkan keterlibatan mutu secara berkelanjutan. Dalam hal ini model serial berperan sebagai penyusun atau penata mata kuliah pada kurikulum agar tercapai pembelajaran yang terstruktur pada setiap jenjang, Sedangkan TQM berperan sebagai pengendalian mutu dalam menjamin outcome pendidikan tinggi. Sehingga integrasi kedua aspek tersebut akan memberikan inovasi baru pada pengembangan kurikulum di pendidikan tinggi. Adapun implementasinya pada setiap jenjang atau tingkat keilmuan harus berdasarkan prinsip-prinsip TQM. Mahasiswa yang mempelajari mata kuliah tingkat dasar hingga profesi harus dijamin kepuasan belajarnya melalui pembelajaran dan fasilitas yang bermutu, selanjutnya untuk mewujudkan hal tersebut diperlukan keterlibatan seluruh aktivitas akademika mulai dari Kaprodi, Dosen dan mahasiswa. Sedangkan untuk menilai ketercapaian mahasiswa dalam pembelajaran dilakukan pengukuran melalui prestasi akademik seperti nilai, pemahaman kompetensi dan pengembangan diri. Terakhir apabila dalam hasil pengukuran tidak sesuai dengan yang diharapkan, maka kurikulum harus dibenahi secara berkelanjutan dengan tetap berkomitmen pada prinsip TQM. 
2144 Strategi Pengembangan Kurikulum Perspektif Pendekatan Total Quality Management (Tqm) di Pendidikan Tinggi - Raqib Alamah Putra, Putri Restina Dewi, Ahmad Jalaludin, Abdul Malik Karim Amrullah DOI: https://doi.org/10.31004/edukatif.v3i5.715

\section{KESIMPULAN}

Pengembangan kurikulum model serial dengan pendekatan TQM layak menjadi salah satu alternatif dalam mewujudkan lulusan yang berkualitas di pendidikan tinggi. Hasil analisis menunjukkan model serial menyusun mata kuliah secara tersistem berdasarkan tingkat keilmuan sedangkan TQM memiliki prinsip yang fokus pada pengendalian mutu. Dengan demikian, pengembangan kurikulum dengan menerapkan strategi model serial berdasarkan prinsip TQM sangat efektif dalam meningkatkan kualitas lulusan di pendidikan tinggi secara berkelanjutan.

\section{UCAPAN TERIMA KASIH}

Ucapan terima kasih diberikan kepada Bapak Dr. Abdul Malik Karim Amrullah, M.Pd.I selaku Dosen Pengampu Mata Kuliah Manajemen Mutu Pendidikan atas bimbingan dalam penyelesaian penelitian. Selanjutnya kritik dan saran sagat diperlukan untuk memperbaiki kekurangan pada penelitian ini.

\section{DAFTAR PUSTAKA}

Academy, S. N. (2012). Assessing 21st Century Skill: Summary Of A Workshop. Washington: Division Of Behaviofal And Social Sciences And Education.

Alhamuddin. (2016). Kurikulum Pendidikan Tinggi Keagamaan Islam: Mutu Dan Relevansi. Al-Murabbi Volume 3, Nomor 1, Juli 2016 ISSN 2406-775X, 3(April), 1-15.

Dikti. (2014). Buku Panduan Kurikulum Pendidikan Tinggi. Jakarta: Direktorat Jenderal Pendidikan Tinggi.

Direktorat Pendidikan Tinggi Keagamaan Islam. (2018). Pengembangan Kurikulum PTKI Mengacu Pada KKNI Dan SN-Dikti.

Hanafi, Y. (2016). Transformasi Kurikulum Mata Kuliah Pendidikan Agama Islam Di Perguruan Tinggi Umum: Dari Paradigma Normatif-Doktriner Menuju Paradigma Historis-Kontekstual. Jurnal Pendidikan Dan Pembelajaran (JPP): Vol. 23, No. 1, April 2016, 23(1), 27-37.

Http://Journal.Um.Ac.Id/Index.Php/Pendidikan-Dan-Pembelajaran/Article/View/10149

Helaluddin. (2018). Redesain Kurikulum Pendidikan Tinggi Islam: Strategi Dalam Menyongsong Era Revolusi Industri 4.0. Jurnal Mudarrisuna: Media Kajian Pendidikan Agama Islam; Vol. 8 No. 2 JulyDesember 2018, 8(2), 258. Https://Doi.Org/10.22373/Jm.V8i2.3224

Kaimuddin. (2015). Pengembangan Kurikulum Pendidikan Tinggi. Jurnal Al-Ta'dib Vol. 8 No. 1, JanuariJuni, 8(1), 19-38.

Kemendikbud. (2012). Undang-Undang N0. 12 Tahun 2012 Tentang Pendidikan Tinggi. Jakarta: Kemendikbud.

Kemendikbud. (2014). Kurikulum Pendidikan Tinggi. Jakarta: Ditjen Pendidikan Tinggi.

Khoiri, N. (2016). Peningkatan Mutu Pendidikan Di Perguruan Tinggi Melalui Implementasi Total Quality Management (TQM). Jurnal Intelegensia; Vol. 04 No. 1 Januari-Juni 2016, 04(1), 40-61.

Maksum, A. (2015). Kurikulum Dan Pembelajaran Di Perguruan Tinggi: Manuju Pendidikan Yang Memberdayakan. Seminar Nasional Hasil Penelitian Pendidikan Dan Pembelajaran, 25-26 April 2015, June, $1-11$.

Marwan, S. (2014). Model Pengembangan Pendidikan Tinggi Islam Di Indonesia. Ulumuna Jurnal Studi Keislaman; Vol. 18 No. 1 (Juni), 18, شمار 89-117.

Nurdin, S. (2018). Pengembangan Kurikulum Dan Rencana Pembelajaran Semester (Rps) Berbasis Kkni Di Perguruan Tinggi. Al-Fikrah: Jurnal Manajemen Pendidikan: Vol. 1 No. 2 September 2018, 5(1), 140- 
2145 Strategi Pengembangan Kurikulum Perspektif Pendekatan Total Quality Management (Tqm) di Pendidikan Tinggi - Raqib Alamah Putra, Putri Restina Dewi, Ahmad Jalaludin, Abdul Malik Karim Amrullah DOI: https://doi.org/10.31004/edukatif.v3i5.715

147. Https://Doi.Org/10.31958/Jaf.V5i1.813

Sayyi. Ach. (2017). Modernisasi Kurikulum Pendidikan Islam Dalam Perspektif Azyumardi Azra. Tadris; Volume. 12, Nomor 1, Juni 2017, 12(1).

Sonia, N. R. (2021). Total Quality Management Dalam Lembaga Perguruan Tinggi. Southeast Asian Journal Of Islamic Education Management Vol. 2 No. 1 (2021), 2(1), 125-139.

Sukmadinata, N. S. (2012). Kurikulum Dan Pembelajaran Kompetensi. Bandung: Refika Aditama.

Suwadi. (2016). Pengembangan Kurikulum Pendidikan Agama Islam Pada Pendidikan Tinggi Mengacu KKNI-SNPT Berparadigma Interkoneksi Di Program Studi PAI FITK UIN Sunan Kalijaga Yogyakarta. Jurnal Pendidikan Agama Islam; Vol. XIII, No. 2, Desember 2016, 2(2), 14-15.

Wafi, A. (2017). Konsep Dasar Kurikulum Pendidikan Agama Islam. Edureligia; Jurnal Pendidikan Agama Islam, 1(2), 133-139. Https://Doi.Org/10.33650/Edureligia.V1i2.741

Wibowo, A. E., Surjasa, D., Banirohim, G., Tausi, H., Setianto, R. H., Budiratmoko, R. M. E., \& Mutia, S. (2020). Kerangka Pelaksanaan Total Quality Management (TQM) Pada Tingkat Perguruan Tinggi. KOCENIN Serial Konferensi No. 1 (2020) Webinar Nasional Cendekiawan Ke 6 Tahun 2020, 1(1), 1-7.

Yusuf, M., \& Sohiron, S. (2019). Manajemen Pembelajaran Pendidikan Tinggi (Implementasi Kurikulum Berbasis KKNI Pada Program Sarjana Melalui Pendekatan Andragogi). Indonesian Journal Of Islamic Educational Management: Vol. 2, No. 2, Oktober 2020, 2(2), 53.

Https://Doi.Org/10.24014/Ijiem.V2i2.7897 